\title{
From the Desk of the Editor
}

\section{Management of Hyperglycemia in ICU setting}

\author{
Dr. Kazi Ali Hassan \\ DOI: https://doi.org/10.3329/bccj.v9i2.56151
}

Bangladesh has a type 2 diabetes mellitus population of $7.8 \%$ and pre-diabetes of $10.1 \%$ and the prevalence is higher in urban areas compared with rural areas ${ }^{1}$.Patients with diabetes are frequently admitted in the hospital with various illnesses and a significant numbers are admitted in the critical care settings like ICU,CCU and HDU. Hyperglycemia in hospital can occur in those with previously undiagnosed diabetes and others with "stress hyperglycemia" that may occur during an acute illness. The American Diabetes Association (ADA) and American Association of Clinical Endocrinologists (AACE) have defined hospital-related hyperglycemia as any blood glucose concentration of more than $7.8 \mathrm{mmol} / \mathrm{l}$ in patients without a prior history of diabetes ${ }^{2}$. In-hospital hyperglycemia is very common condition and is an important marker of mortality in patients with and without a past history of diabetes $^{3}$. Patients with diabetes who are hospitalized for medical or surgical illnesses have longer hospital stay in comparison to non diabetic patients ${ }^{4}$.

Diabetes is a disease expensive to treat and it has been found in a study that about $50 \%$ of total cost of medical expenditures attributed to diabetes in USA are hospital inpatient care 5 .

In acute illness hyperglycemia leads to release of counter regulatory hormones (cortisol, glucagon), and pro-inflammatory cytokines (TNF- $\alpha$, IL-6) leading to impaired immune function. All of these changes can lead to increased risk of infection, impaired wound healing, deranged kidney function,prolonged hospital stay and mortality ${ }^{6}$.

For the past one and a half year we are devastated with covid-19 pandemic and diabetes has been found the second highest comorbidity in COVID-19 patients and a significant number of diabetic patients with severe COVID-19 infections are admitted in $\mathrm{ICU}^{7}$. Diabetic patients with covid-19 are more likely to die compared with those without diabetes and in-hospital morbidity and mortality is significantly lower in those with well controlled diabetes ${ }^{8}$. For reducing the morbidity and mortality, length of stay and cost of hospital treatment,patients with hyperglycemia should be promptly identified upon admission and properly managed.

In the critical care setting, intravenous insulin infusion is the most effective and recommended method for controlling hyperglycemia and achieving glycemic targets.In ICU patients insulin should be started if there is persistent hyperglycemia of more than $10 \mathrm{mmol} / \mathrm{l}^{9}$.

The American Diabetes Association (ADA) and American Association of Clinical Endocrinologist (AACE) guidelines recommend a glucose level between 7.8 and $10.0 \mathrm{mmol} / 1$ for the majority of critically ill patients and lower glucose targets between 6.1 and $7.8 \mathrm{mmol} / \mathrm{l}$ in selected patients (i.e.cardiac surgical patients, patients with stable glycemic control without hypoglycemia). ${ }^{2,9}$

The Society of Critical Care Medicine (SCCM), however, differs from the other bodies and recommends initiation of intravenous insulin if the blood glucose is $\geq 8.3 \mathrm{mmol} / \mathrm{l}^{10}$. Several studies have found that intensive intravenous insulin therapy significantly reduced the mortality and morbidity in critically ill patients with hyperglycemia ${ }^{11,12}$. Continuous intravenous short or rapid acting insulin infusion is the recommended method to achieve the desired glycemic control in critically ill patients. Adminstration of intravenous insulin requires an insulin pump which will deliver the required insulin dose in unit per hour ${ }^{13,14,15}$. There are different protocols/algorithms for insulin infusion available and there is no clear evidence that the one is better than the other. There are also computer-based algorithms available to help the medical staff adjusting the insulin infusion rate according to the blood sugar level ${ }^{16,17}$. Capillary point of care (POC) testing is the recommended approach to monitor blood glucose in the ICU-setting with several things to be kept in mind which might affect the blood sugar value such as hemoglobin level ${ }^{18}$. Blood sugar should be monitored every 1 to 2 hours in patients receiving intravenous insulin.

Hypoglycemia, defined as blood sugar less than $3.9 \mathrm{mmol} / \mathrm{l}$ is the commonest side effects of intravenous insulin in critically ill patients and the incidence varies depending on the intensity of glycemic control ${ }^{13}$. Frequent monitoring of blood sugar in patients receiving intravenous insulin infusion when the blood sugar is near to the lower limit of the target is the best way to prevent severe hypoglycemia $(<2.2 \mathrm{mmol} / \mathrm{l})$. Intravenous insulin infusion should be continued till the patient is clinically stable and has been started on enteral/ oral feeding and the blood sugar is reasonably controlled.Stable patients should be shifted to a basal/bolus and correctional subcutaneous insulin regimen before the insulin infusion is stopped to avoid a significant loss of glucose control because intravenous insulin has short half life $(<10$ minutes) and should not be discontinued until subcutaneous insulin has been started. When switching from intravenous to subcutaneous insulin, the short acting soluble insulin should be given 30 minutes before, rapid acting insulin analogue 10 minutes before and the intermediate or long acting insulin 2 to 3 hours before discontinuing the intravenous insulin.

Basal-bolus regimen addresses the 3 components of insulin requirement in our body: basal insulin (required to reduce fasting sugar and between meals), nutritional or prandial insulin (required to reduce the post meal glucose), and supplemental insulin (additional dose of bolus insulin required for unexpected glucose rise). Correctional or supplemental insulin is given just before meal together with pre meal insulin ${ }^{19}$. American Diabetes Association (ADA) and 
other international bodies have recommended that hospitalized diabetic patients who are not critically ill should receive basal insulin along with scheduled pre prandial doses of short or rapid-acting insulin and additional supplemental short or rapid-acting insulin to correct pre meal hyperglycemia ${ }^{20}$. Blood sugar should be monitored before and 2 hours each meal.

Sliding-scale of subcutaneous short or rapid-acting insulin is still widely used in most of the hospitalized patients in Bangladesh but by this method of insulin delivery is not in a physiological manner and can lead to wide fluctuation in blood sugar levels leading to erratic glycemic control ${ }^{21}$. Sliding- scale of insulin is strongly discouraged in most of the international recommendations as there is higher risk of hyperglycemia and hypoglycemia (roller coaster) and has to be found an ineffective means of achieving optimal glycemic control. For any hospitalized patient receiving enteral or parental feeding with or without history of diabetes, blood glucose testing should be initiated and can be discontinued if blood glucose values are less than $7.8 \mathrm{mmol} /$ liter for $24-48 \mathrm{~h}$ after achievement of desired caloric intake. ${ }^{22}$.

The burden of diabetes management in ICU settings falls mostly on the junior medical staffs but the knowledge and training among them to a large extent is sub-optimal ${ }^{23}$. Management of diabetes in critically patients should be part of training of the junior medical staff and diabetes educational goals should focus on insulin administration and dose adjustment, blood sugar monitoring, prevention and treatment of hypoglycemia. ICU, CCU and HDU should have their own written policies, protocols, algorithms and order sets for proper and effective management of hyperglycemia.

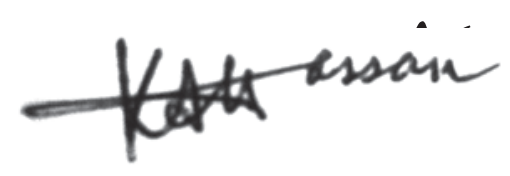

Dr. Kazi Ali Hassan

Senior Consultant,

Department of Endocrinology

United Hospital, Dhaka

International Secretary, Bangladesh Endocrine Society

E-mail: hassan.kazi.1959@gmail.com

\section{References}

1. Akhter S,Nasir JA,Sarwar A,Majeed R,Salam MA,Billah B.Prevalence of diabetes and pre-diabetes in Bangladesh: a systematic review and meta-analysis. BMJ Open. 2020, 9;10(9):e036086. doi: 10.1136/bmjopen-2019-036086.

2. Moghissi ES, Korytkowski MT, Dinardo MM, Hellman R, Hirsch IB, Inzucchi S, Ismail-Beigi F, Kirkman MS, Umpierrez GE. American Association of Clinical Endocrinologists and American Diabetes Association consensus statement on inpatient glycemic control. Diabetes Care. 2009;32:1119-1131.
3. Umpierrez GE,Isaacs SD,Bazargan N,You X,Thaler LM,Kitabchi AE.Hyperglycemia: An independent marker of in-hospital mortality in patients with undiagnosed diabetes.Jclin Endo Metab Volume 87, Issue 3, 2002, 978-982, https://doi.org/10.1210/jcem.87.3.8341

4. Valent F,Tonutti L,Grimaldi F. Does diabetes mellitus comorbidity affect in-hospital mortality and length of stay? Analysis of administrative data in an Italian Academic Hospital Acta Diabetol.2017; 54:1081-1090 DOI: 10.1007/s00592-017-1050-6

5. American Diabetes Association: Economic costs of diabetes in the U.S. in 2007. Diabetes Care. 2008 31:596-615

6. Stentz FB, Umpierrez GE, Cuervo R, Kitabchi AE Proinflammatory cytokines, markers of cardiovascular risks, oxidative stress, and lipid peroxidation in patients with hyperglycemic crises. Diabetes. 2004;53:2079-2086

7. Yang J,Zheng Y,Gou X,Pu K,Chen Z. Prevalence of comorbidities and its effects in patients infected with SARS-CoV-2: a systematic review and meta-analysis. Int J Infect Dis. 2020; 94: 91-95

8. Zhu L,She Z-G,Cheng X,Qin J J,Zhang X-J. Association of Blood Glucose Control and Outcomes in Patients with COVID-19 and Pre-existing Type 2 Diabetes. Cell Metabolism.2020;31; 1068-1077

9. Standards of Medical Care in Diabetes - 2021. Diabetes Care 2021;44(Suppl. 1):S73-S84

10. Jacobi J, Bircher N, Krinsley J, Agus M, Braithwaite SS, Duutschman C,et al. Guidelines for the use of an insulin infusion for the management of hyperglycemia in critically ill patients. Critical Care Medicine. 2012;40:3251-3276

11. Van den Berghe G, Wouters P, Weekers F, Verwaest C, Bruyninckx F, Schetz M, Vasselaers D, Ferdinande P, Bouillon R, Lauwers P. Intensive insulin therapy in critically ill patients. New England Journal of Medicine. 2001;345:1359-1367.

12. Van den Berghe G, Wilmer A, Hermans G, Meersseman W, Wouters PJ, Milants I, Van Wijngaerden E, Bobbaers H, Bouillon R. Intensive insulin therapy in the medical ICU. New England Journal of Medicine. 2006;354:449-461

13. Krikorian A, Ismail-Beigi F, Moghissi ES. Comparisons of different insulin infusion protocols: a review of recent literature. Current Opinion in Clinical Nutrition \& Metabolic Care. 2010;13:198-204.

14. George S, Dale J, Stanisstreet D. A guideline for the use of variable rate intravenous insulin infusion in medical inpatients. Diabetic Medicine. 2015;32:706-713

15. Gauthier L, Ferguson J, Dubé AI, Nguyen PV, Beauchesne MF, Boutin JM. Assessment of quality of glycemic control in intensive care patients treated with an insulin infusion at a teaching hospital. Can J Diabetes. 2014 Apr;38(2):139-43

16. Ullal J, Aloi JA. Subcutaneous insulin dosing calculators for inpatient glucose control. Current Diabetes Reports. 2019;19:120

17. Davidson PC, Steed RD, Bode BW. Glucommander. A computer-directed intravenous insulin system shown to be safe, simple, and effective in $120,618 \mathrm{~h}$ of operation. Diabetes Care. $2005 ; 28: 2418-2423$

18. Rice MJ, Smith JL, Coursin DB. Glucose measurement in the ICU: Regulatory intersects reality. Critical Care Medicine. 2017;45:741-743.

19. JAPI.Special Issue on Consensus Statements on Insulin Therapy:JULY 2014.VOL.62

20. American Diabetes Association: Standards of medical care in diabetes (Position Statement). Diabetes Care 30 (Suppl. 1):S4-S41, 2007 
21. Queale WS. et al.Glycemic control and sliding scale insulin use in medical inpatients with diabetes mellitus. Arch Int Med 1997;157: (5):545-52

22. Umpierrez GE,Hellman R,Korytkowski MT,Kosiborod M,Maynard GA, et al.Management of Hyperglycemia in Hospitalized Patients in Non-Critical Care Setting: An Endocrine Society Clinical Practice Guideline.The Journal of Clinical Endocrinology \& Metabolism, 2012; 97(1):16-38
23. George JT, Warriner D, McGrane DJ, Rozario KS, Price HC, Wilmot EG, Kar P, Stratton IM, Jude EB, McKay GA. Team obotTDS. Lack of confidence among trainee doctors in the management of diabetes: the Trainees Own Perception of Delivery of Care (TOPDOC) Diabetes Study. QJM. 2011;104:761-766. 